\title{
Risk Assessment of Shield Tunnel Construction in Karst Strata Based on Fuzzy Analytic Hierarchy Process and Cloud Model
}

\author{
Guowang Meng $\mathbb{D}^{1,2}$ Yangchun Ye $\mathbb{D}^{1},{ }^{1}$ Bo Wu $\mathbb{D}^{1,2,3}$ Guijun Luo, ${ }^{4}$ Xu Zhang, \\ Zhiqiang Zhou, ${ }^{4}$ and Wentao Sun ${ }^{1}$ \\ ${ }^{1}$ College of Civil Engineering and Architecture, Guangxi University, Nanning 530004, China \\ ${ }^{2}$ Key Laboratory of Disaster Prevention and Structural Safety of Ministry of Education, Guangxi University, \\ Nanning 530004, China \\ ${ }^{3}$ School of Civil and Architectural Engineering, East China University of Technology, Nanchang 330013, China \\ ${ }^{4}$ China Construction Fifth Engineering Bureau Civil Engineering Co., Ltd., Changsha 410004, China \\ Correspondence should be addressed to Yangchun Ye; 1213090794@qq.com and Bo Wu; wubo@gxu.edu.cn
}

Received 13 July 2021; Revised 17 October 2021; Accepted 22 October 2021; Published 2 November 2021

Academic Editor: Nur Izzi Md. Yusoff

Copyright (c) 2021 Guowang Meng et al. This is an open access article distributed under the Creative Commons Attribution License, which permits unrestricted use, distribution, and reproduction in any medium, provided the original work is properly cited.

\begin{abstract}
Karst is an unfavorable geology that is very undesirable in tunnel construction. It is extremely risky due to the complexity and fuzziness of shield excavation in karst strata. To reduce the construction risk of shield tunneling in karst strata, a risk assessment method based on cloud model and fuzzy analytic hierarchy process (FAHP) is proposed. A risk assessment index system is established, including four first-level indices of karst geological conditions, hydrogeological conditions, tunnel design, and shield construction, as well as seventeen second-level indices. Fuzzy analytic hierarchy process is used to determine the evaluation indices weights. The numerical characteristics of each index and the risk cloud diagram are obtained via the backward cloud generator and forward cloud generator, respectively. The certainty degrees of the assessment indices corresponding to each risk level are calculated, and the final risk level is determined based on the comparison of the risk cloud diagram and the principle of maximum certainty. The proposed model is applied to the risk analysis and calculation of shield tunnel engineering, and the risk assessment results indicate that the comprehensive risk level of shield tunnel construction in karst strata is level II, which is consistent with the actual project. It demonstrates that the proposed method can provide a reference for the risk assessment of shield tunnels construction in karst strata.
\end{abstract}

\section{Introduction}

Shield method has become the preferred construction method for subway engineering due to its advantages of technology, economy, safety, and environmental protection. Meanwhile, the special geologies encountered in subway construction projects have been increasing. Because of the low mechanical strength and poor stability of karst strata, water inrush, collapse, and other accidents are easy to occur in tunnel construction of tunnel crossing the karst strata, resulting in heavy economic losses and casualties [1]. At the same time, shield tunneling in karst strata will inevitably cause vibration of the surrounding rock, resulting in surface subsidence and threats to adjacent building safety, which has a great impact on the safety of subway construction. Therefore, it is significant to assess the risk of shield tunneling in karst strata.

The safety of shield tunnel construction in karst strata is affected by multiple risk factors, which are complex, fuzzy, and random. Many scholars have researched the risk of tunnel crossing karst strata and proposed a number of risk assessment methods, such as analytic hierarchy process [2], fuzzy comprehensive evaluation method [3], extension theory [4], BP neural network [5], and set pair analysis [6]. However, most of these studies are focused on highway tunnels and railway tunnels, while fewer studies have been 
conducted on the risk assessment of shield tunnel construction in karst strata, which has been deeply studied by the following scholars. Huang et al. [7] used BP neural network method to establish a prediction model of shield tunneling parameters in karst strata, which is conducive for selecting reasonable shield tunneling parameters, so as to guarantee safe and efficient shield tunneling. Zhao et al. [8] analyzed the risk level of shield tunnels crossing karst areas based on analytic hierarchy process and fuzzy comprehensive evaluation method, and proposed measures to reduce the risk of construction. Zhou et al. [9] established a risk assessment model for shield tunnel construction in karst strata based on Bayesian network, and applied this model to Dalian Metro Line 5 and concluded that the risk assessment results are consistent with the actual situation. Lyu et al. [10-13] studied the influence of external environmental factors on the safety of metro systems and established a multi-indicator system based on fuzzy analytic hierarchy process to assess the risk level of metro systems. The abovementioned scholars used different methods to analyze the risks of shield construction in karst strata and achieved good results. They have fully considered the natural factors that may lead to construction risks but have considered less on design factors and construction factors that are only mentioned in the literature [8]. At the same time, all of these risk assessment methods have their own disadvantages; for example, the analytic hierarchy process is highly subjective for experts in assessing construction risks so that it cannot reflect the fuzziness and randomness of engineering well, and the BP neural network method requires a large amount of historical data to construct learning samples.

To address these problems, this paper proposes a risk assessment model for shield tunnel construction in karst strata based on fuzzy analytic hierarchy process and cloud model theory, aiming to improve the accuracy of risk assessment for shield tunnel construction in karst strata so as to guarantee construction safety.

\section{Theoretical Methods}

2.1. Cloud Model Theory. The cloud model theory proposed by $\mathrm{Li}$-an academician of Chinese Academy of Engineering-in 1995 combines probability theory and fuzzy mathematics theory and fully considers the randomness and uncertainty in practical projects. The cloud model can realize a good conversion between qualitative concepts and quantitative values by mutual transformation of cloud numerical characteristic values and cloud drops through cloud generator $[14,15]$. In the field of underground engineering, the cloud model has been successfully applied in the risk assessment of rock burst in deep-buried underground caverns, the structural damage evaluation for subway shield tunnel, and to evaluate the risk of tunnel water inrush [16-19].

2.1.1. Cloud and Cloud Numerical Characteristics. Let $X$ be an ordinary set, and $X=\{x\}$ be the universe of discourse. Assuming that $A$ is a fuzzy set in the universe of discourse, for any element $x$ in the universe of $X$, there exists a random number $\mu_{A}(x)$ with stable tendency called the certainty degree of $x$ with respect to $A$, that is, $\mu_{A}: X \longrightarrow[0,1], \forall x \in X$, $x \longrightarrow \mu_{A}(x)$. The distribution of the certainty degree $\mu_{A}(x)$ on the universe $X$ is called a cloud, and each $\xi\left(x, \mu_{A}(x)\right)$ is called a cloud drop [20,21].

The numerical characteristics of the cloud model are represented by three values of expectation (Ex), entropy $(E n)$, and hyper entropy $(\mathrm{He})$. Expectation reflecting the qualitative characteristics of the evaluation objects is the central position of all cloud drops in the universe of discourse; entropy reflecting the discrete degree of cloud drops indicates the fuzziness and randomness of cloud drops in the universe; hyper entropy reflecting the uncertainty degree of entropy indicates the condensation degree of cloud drops. For example, Figure 1 shows a normal cloud with $E x=0, E n=0.3$, $H e=0.02$, and the number of cloud drops is 3000 . The three numerical characteristics of cloud model can be calculated by

$$
\left\{\begin{array}{l}
E x=\frac{\left(L_{\max }+L_{\min }\right),}{2} \\
E n=\frac{\left(L_{\max }-L_{\min }\right)}{6}, \\
H e=k,
\end{array}\right.
$$

where $L_{\max }$ and $L_{\min }$ are the maximum and minimum boundary values of the evaluation level, respectively. $k$ is a constant, which can be set to a value that makes the thickness of the cloud more reasonable. Generally, it is one percent of the maximum value of the evaluation index. In this paper, $k$ is 0.01 .

2.1.2. Cloud Generator. The conversion of qualitative concepts and quantitative values in the cloud model is realized by cloud generators that are divided into forward cloud generators (FCG) and backward cloud generators (BCG), as shown in Figure 2. The forward cloud generator obtains cloud drops by three numerical characteristics of clouds, which is the process of converting qualitative concepts into quantitative values; the backward cloud generator, in contrast to the forward cloud generator, determines three numerical characteristics of clouds through the distribution of cloud drops, which is the process of converting quantitative values into qualitative concepts [22]. In this paper, the forward normal cloud generator is used to analyze the risk of shield tunnel construction in karst strata. The specific algorithm steps are shown in Figure 3, and the calculation process of the algorithm is realized by MATLAB software.

2.2. Fuzzy Analytic Hierarchy Process (FAHP). Analytic hierarchy process (AHP) is a hierarchical weighted decision analysis method proposed by Thomas Saaty, a professor at the University of Pittsburgh. AHP constructs a paired comparison matrix to obtain indices weights through expert scoring, which can systematize complex issues. However, the expert evaluation used in the AHP is absolute, while in 


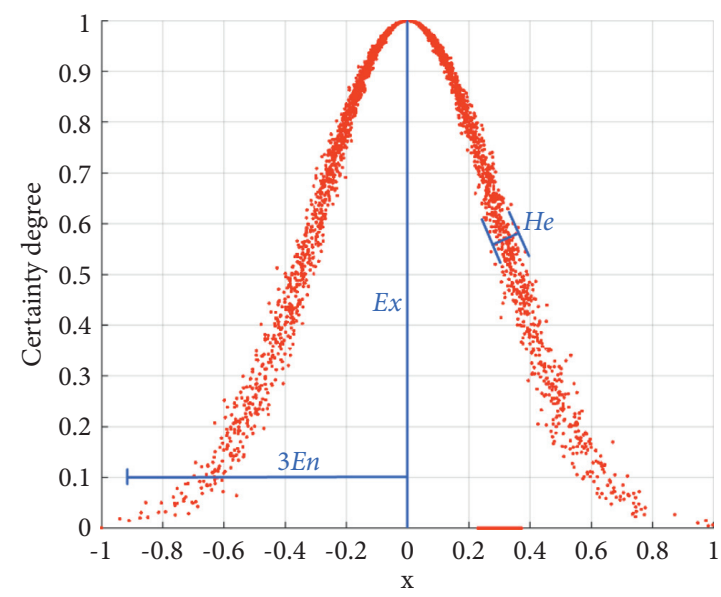

FIgURE 1: A normal cloud and its numerical characteristics.

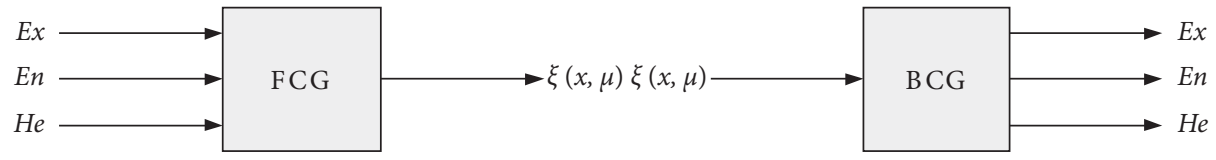

FIgURE 2: Cloud generators.

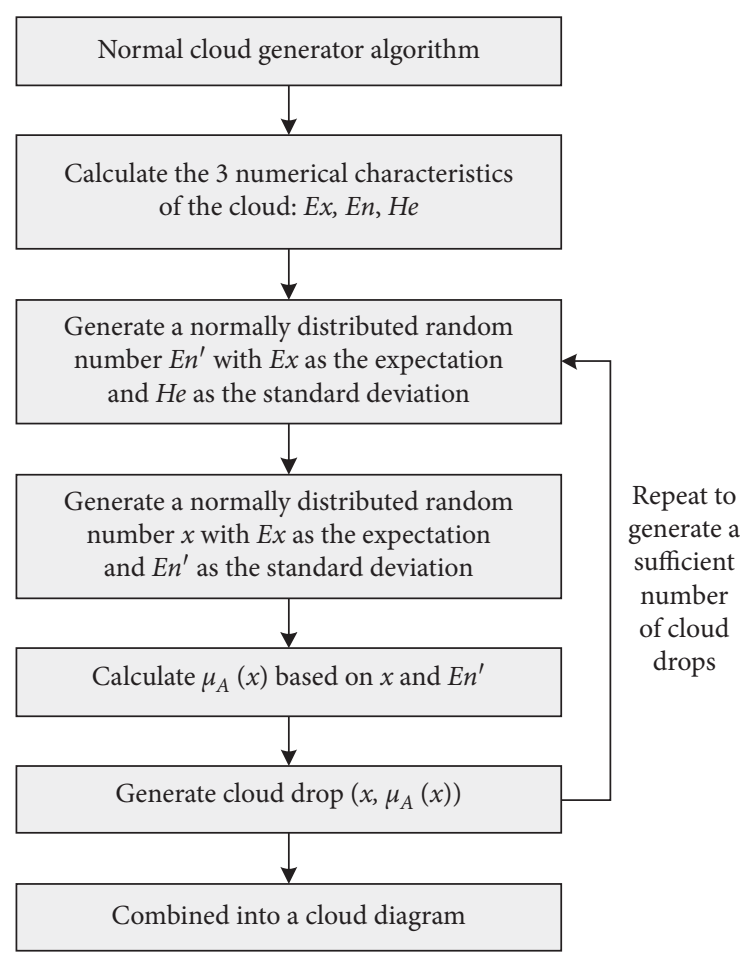

FIGURE 3: Steps of forward normal cloud generator algorithm.

practice experts often give some vague information (for instance, the most probable value and the maximum value) when evaluating risk factors. Hence, the AHP does not reflect the experts' judgment well, which will adversely affect the results of risk assessment. Fuzzy analytic hierarchy process (FAHP) combining fuzzy mathematics with traditional analytic hierarchy process is generally divided into three types: interval FAHP, triangular FAHP, and trapezoidal FAHP. Among them, triangular FAHP uses triangular fuzzy number to express the relative importance between factors. The medium value of the triangular fuzzy number indicates the most probable value, and the two boundary values indicate the minimum and maximum values, respectively. Consequently, the triangular FAHP can well capture the fuzzy information provided by experts and effectively express the fuzziness of experts' judgment and reduce the influence of experts' personal preferences on scoring. [23]. As a result, the risk indices weights obtained by FAHP are more appropriate for practical engineering.

\subsubsection{Constructing the Fuzzy Complementary Judgment} Matrix. According to the risk evaluation system, experts are invited to apply the 0.1-0.9 complementary fuzzy scaling method (Table 1) to compare all indices at each level with each other. Then, the fuzzy complementary judgment matrix $A$ can be constructed by the following equation:

$$
A=\left(a_{i j}\right)_{n \times n}=\left\{\begin{array}{cccc}
a_{11} & a_{12} & \cdots & a_{1 n} \\
a_{21} & a_{22} & \cdots & a_{2 n} \\
\vdots & \vdots & \ddots & \vdots \\
a_{n 1} & a_{n 2} & \cdots & a_{n n}
\end{array}\right\},
$$

where $a_{i j}=\left(l_{i j}, m_{i j}, u_{i j}\right)$ is the triangular fuzzy number which indicates the importance degree of index $i$ to index $j . l_{i j}, m_{i j}$, and $u_{i j}$ denote the lower bound, most likely value, and upper bound of the triangular fuzzy number, respectively, satisfying $a_{i j}+a_{j i}=1, l_{i j}+u_{j i}=m_{i j}+m_{j i}=u_{i j}+l_{j i}=1$. The result of $u_{i j}-l_{i j}$ denotes the degree of fuzziness. When the value is 0 , it 
TABLE 1: The 0.1-0.9 complementary fuzzy scaling method.

\begin{tabular}{lc}
\hline Scale & Meaning \\
\hline 0.5 & Index $i$ and index $j$ are equally important \\
0.6 & Index $i$ is slightly more important than index $j$ \\
0.7 & Index $i$ is obviously more important than index $j$ \\
0.8 & Index $i$ is significantly more important than index $j$ \\
0.9 & Index $i$ is absolutely more important than index $j$ \\
$0.1,0.2,0.3,0.4,0.5$ & Complementarity, inverse comparison of index $i$ with index $j$ \\
\hline
\end{tabular}

means that no fuzziness exists in the expert's judgment. Assume that $d$ experts are invited to score and each expert has the same weight. Then, aij can be calculated by the following equation:

$$
a_{i j}=\frac{a_{i j 1}+a_{i j 2}+\cdots a_{i j t}}{d} .
$$

2.2.2. Determining the Initial Weights. In the fuzzy complementary judgment matrix, the initial weight of index $i$ relative to the index at the upper level $\widetilde{w}_{i}$ can be calculated according to the following equations:

$$
\begin{aligned}
\tilde{w}_{i} & =\frac{\sum_{j=1}^{n} a_{i j}}{\sum_{i=1}^{n} \sum_{j=1}^{n} a_{i j}}, \quad i=1,2, \ldots, n, \\
\frac{1}{a_{i j}} & =\left(\frac{1}{u_{i j}}, \frac{1}{m_{i j}}, \frac{1}{l_{i j}}\right), \\
\frac{\sum_{j=1}^{n} a_{i j}}{\sum_{i=1}^{n} \sum_{j=1}^{n} a_{i j}} & =\left(\frac{\sum_{j=1}^{n} l_{i j}}{\sum_{i=1}^{n} \sum_{j=1}^{n} u_{i j}}, \frac{\sum_{j=1}^{n} m_{i j}}{\sum_{i=1}^{n} \sum_{j=1}^{n} m_{i j}}, \frac{\sum_{j=1}^{n} u_{i j}}{\sum_{i=1}^{n} \sum_{j=1}^{n} l_{i j}}\right) .
\end{aligned}
$$

\subsubsection{Constructing the Fuzzy Consistency Possibility Matrix.}

The fuzzy complementary judgment matrix constructed by expert scoring does not always meet the consistency requirements, while the traditional consistency checking process is too tedious. In order to work out these problems, the fuzzy consistency probability matrix is introduced in this paper [24]. Comparing the initial weights with each other, let $\widetilde{w}_{i}=\left(l_{i}, m_{i}, u_{i}\right)$ and $\widetilde{w}_{j}=\left(l_{j}, m_{j}, u_{j}\right)$, then the possible degree $p_{i j}$ of the initial weight $\widetilde{w}_{i} \geq \widetilde{w}_{j}$ can be calculated by the following equation:

$$
\begin{aligned}
p_{i j}= & \lambda \max \left\{1-\max \left(\frac{m_{j}-l_{i}}{m_{i}-l_{i}+m_{j}-l_{j}}, 0\right), 0\right\} \\
& +(1-\lambda) \max \left\{1-\max \left(\frac{u_{j}-m_{i}}{u_{i}-m_{i}+u_{j}-m_{j}}, 0\right), 0\right\},
\end{aligned}
$$

where $\lambda$ indicates the assessor's preference for risk with three main situations: $\lambda \in(0,0.5), \lambda \in(0.5,1)$, and $\lambda=0.5$, which indicate that the assessor is risk averse, preferred, and neutral, respectively. In this paper, $\lambda=0.5$.
Based on the possible degree calculated above, the fuzzy consistency possibility matrix $R$ can be constructed by

$$
\begin{aligned}
& R=\left(r_{i j}\right)_{n \times n}=\left\{\begin{array}{cccc}
r_{11} & r_{12} & \cdots & r_{1 n} \\
r_{21} & r_{22} & \cdots & r_{2 n} \\
\vdots & \vdots & \ddots & \vdots \\
r_{n 1} & r_{n 2} & \cdots & r_{n n}
\end{array}\right\}, \\
& r_{i j}=\frac{r_{i}-r_{j}}{2(n-1)}+\frac{1}{2}, \\
& r_{i}=\sum_{z=1}^{n} p_{i z}, i=1,2, \ldots, n, \quad z=1,2, \ldots, n .
\end{aligned}
$$

2.2.4. Determining the Final Weights. After obtaining the fuzzy consistency possibility matrix, the final weights of the indices can be calculated by the following equation:

$$
w_{i}=\frac{\sum_{j=1}^{n} r_{i j}+(n / 2)-1}{n(n-1)}
$$

\section{FAHP-Cloud Model Risk Assessment Process}

Based on cloud model theory and fuzzy analytic hierarchy process, a multi-index system is proposed to evaluate the risk of shield tunnel construction in karst strata, as shown in Figure 4, for the risk assessment flow chart. The assessment process is divided into two parts: (1) risk assessment system and (2) FAHP-cloud model assessment. The risk assessment system-a hierarchical analysis structure-from top to bottom is the target layer (risk assessment of shield construction in karst strata), criterion layer (first-level evaluation indices), and factor layer (second-level evaluation indices). The FAHP calculates the initial and final weights of the risk assessment indices by constructing the fuzzy complementary judgment matrix and the fuzzy consistency possibility matrix, respectively. According to the obtained weights, the numerical characteristics of the assessment indices are calculated by cloud model and the risk cloud diagram is generated to initially determine the risk level of shield tunnel construction in karst strata. In addition, the risk assessment results need to be verified by (1) calculating the certainty degree of the comprehensive cloud numerical characteristics for each risk level and verifying the accuracy 


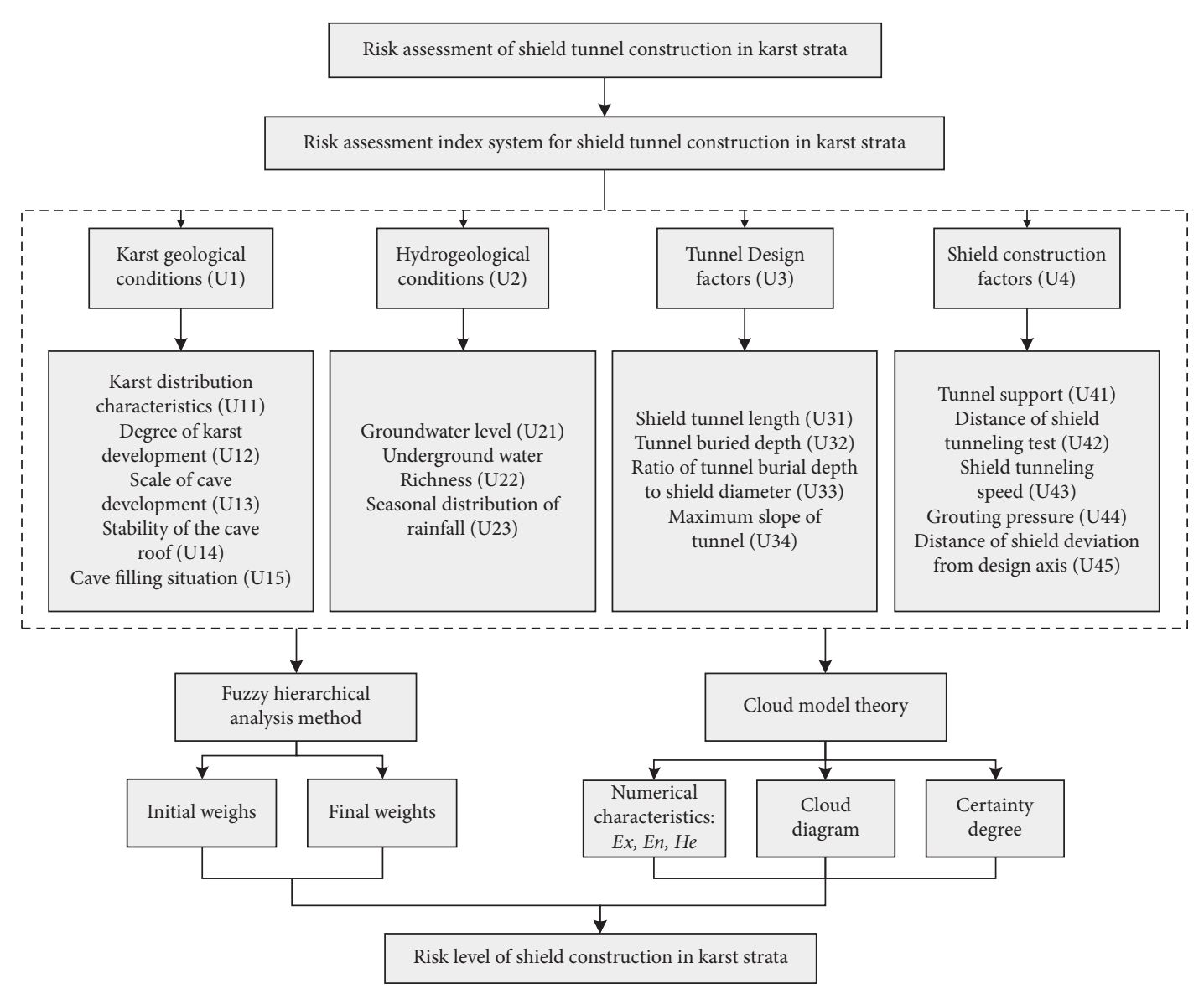

FIGURE 4: Risk assessment model based on FAHP-cloud model.

of this risk assessment method according to the principle of maximum certainty; (2) comparing the assessment results with the results of the fuzzy comprehensive evaluation method, the set pair analysis method, and the extension theory; and (3) verifying the results according to the actual tunneling situation of the shield tunnel.

3.1. Establishing the Assessment Index System. In the process of shield tunneling in karst strata, many factors affect the safety of the tunnel. Based on the previous research results $[25,26]$ and related norms [27-29], indices that have a great impact on tunnel safety are selected for risk evaluation. The karst geological conditions, hydrogeological conditions, tunnel design, and shield construction are selected as the first-level evaluation indices, and then each first-level index is divided into several second-level evaluation indices. The first-level indices and second-level indices are combined to establish a risk assessment index system, as shown in Figure 4. According to the abovementioned literature and norms, the risk of shield tunnel construction in karst strata is divided into 4 levels: I (low risk), II (moderate risk), III (high risk), and IV (higher risk). The standard cloud numerical characteristics are calculated by equation (1), and the risk level criteria are shown in Table 2. The risk level classification criteria corresponding to the seventeen second-level indices are shown in Table 3.
3.1.1. Karst Geological Conditions (U1). Karst distribution characteristics (U11) are an important factor affecting the quality of tunnel construction. If karst is homogeneously distributed, karst treatment is relatively simple; inhomogeneous distribution of karst not only increases the difficulty of karst treatment but also poses a great threat to the surrounding environment and personnel safety during construction.

Karst development degree (U12) is determined by three indicators reflecting the characteristics of karst development, namely, hole-bore percentage, line karst rate, and units-inflow of drilling. The higher the karst development degree, the more the difficulty of cave treatment and the greater the potential danger of construction.

The scale of cave development (U13) is expressed by cave height. The larger the scale of caves, the greater the dissolution of groundwater on soluble rocks. The treatment measures for caves of different sizes are also different. Small caves are filled with grout directly, while large caves are treated by filling the cavity with medium sand first and then grouting.

The stability of the cave roof (U14) is affected by many factors, including roof thickness, cave height, geological structure, load size, and so on [30]. When tunnel construction encounters a cave with an unstable roof, it is highly likely to collapse if measures are not taken in time, resulting in significant economic losses and casualties. 
TABLE 2: The risk level criteria.

\begin{tabular}{lccc}
\hline Risk level & Risk acceptance criteria & Value & Standard cloud numerical characteristics \\
\hline I & Negligible risk & {$[0,0.25)$} & $(0.125,0.042,0.01)$ \\
II & Strengthen monitoring and management & {$[0.25,0.50)$} & $(0.375,0.042,0.01)$ \\
III & Take measures to reduce risk & {$[0.50,0.75)$} & $(0.625,0.042,0.01)$ \\
IV & Unacceptable risk, rework the construction scheme & {$[0.75,1)$} & $(0.875,0.042,0.01)$ \\
\hline
\end{tabular}

TABLE 3: Risk level classification criteria for evaluation indices.

\begin{tabular}{|c|c|c|c|c|c|}
\hline \multirow{2}{*}{$\begin{array}{l}\text { Serial } \\
\text { number }\end{array}$} & \multirow{2}{*}{ Assessment indices } & \multicolumn{4}{|c|}{ Risk level } \\
\hline & & I & II & III & IV \\
\hline U11 & Karst distribution characteristics & $\begin{array}{c}\text { Very } \\
\text { homogeneous }\end{array}$ & Homogeneous & Inhomogeneous & $\begin{array}{c}\text { Very } \\
\text { inhomogeneous }\end{array}$ \\
\hline U12 & Degree of karst development & Undeveloped & $\begin{array}{l}\text { Slightly } \\
\text { developed }\end{array}$ & $\begin{array}{l}\text { Moderate } \\
\text { developed }\end{array}$ & Strongly developed \\
\hline U13 & Scale of cave development (m) & {$[0,3)$} & {$[3,5)$} & {$[5,10)$} & {$[10,+\infty)$} \\
\hline U14 & Stability of the cave roof & Very stable & Stable & Unstable & Very unstable \\
\hline U15 & Cave filling situation & Completely filled & Partially filled & Empty & Filled by karst water \\
\hline $\mathrm{U} 21$ & Groundwater level (m) & {$[0,10)$} & {$[10,20)$} & {$[20,40)$} & {$[40,+\infty)$} \\
\hline $\mathrm{U} 22$ & Underground water richness & Poor & Slight & Moderate & Rich \\
\hline $\mathrm{U} 23$ & Seasonal distribution of rainfall & $\begin{array}{c}\text { Very } \\
\text { homogeneous }\end{array}$ & Homogeneous & Concentrated & Very concentrated \\
\hline U31 & Shield tunnel length (m) & $(0,500]$ & $(500,1000]$ & $(1000,3000]$ & $(3000,+\infty)$ \\
\hline $\mathrm{U} 32$ & Tunnel buried depth (m) & $(+\infty, 20]$ & $(20,10]$ & $(10,5]$ & $(5,0]$ \\
\hline U33 & $\begin{array}{c}\text { Ratio of tunnel burial depth to shield } \\
\text { diameter }\end{array}$ & $(+\infty, 3]$ & $(3,2]$ & $(2,1]$ & $(1,0)$ \\
\hline $\mathrm{U} 34$ & Maximum slope of tunnel (\%o) & $(0,25]$ & $(25,30]$ & $(30,35]$ & $(35,40]$ \\
\hline U41 & Tunnel support & Very reasonable & Reasonable & Unreasonable & Very unreasonable \\
\hline U42 & Distance of shield tunneling test $(\mathrm{m})$ & {$[200,300]$} & {$[100,200)$} & {$[50,100)$} & {$[0,50)$} \\
\hline $\mathrm{U} 43$ & Shield tunneling speed (Loops/day) & $(0,5]$ & $(5,10]$ & $(10,15]$ & $(15,20]$ \\
\hline U44 & Grouting pressure $(\mathrm{MPa})$ & {$[0.15,0.25)$} & {$[0.25,0.634)$} & {$[0.634,1)$} & {$[1,+\infty)$} \\
\hline U45 & $\begin{array}{l}\text { Distance of shield deviation from design } \\
\text { axis (mm) }\end{array}$ & {$[0,10)$} & {$[10,30)$} & {$[30,50)$} & {$[50,+\infty)$} \\
\hline
\end{tabular}

The filling of karst caves (U15) mainly includes four situations: completely filled, partial filled, empty, and filled by karst water. Cave treatment measures for different filling situations are quite different, among which the cave filled by a large amount of karst water is the most difficult to deal with. The cavities need to be pumped clean of karst water first, and then filled with fine sand and cement mortar.

3.1.2. Hydrogeological Conditions (U2). For the construction of underground projects such as tunnel excavation, the groundwater level (U21) directly affects tunnel safety. Since karst is developed by the dissolution of water on soluble rocks, when the groundwater level is high, it is not only easy to cause tunnel burst but also promote the development of karst.

Underground water richness (U22) reflects the water content of carbonate rock caves in the project area. Waterrich caves are difficult to handle and prone to water inrush, which bring great hazards to tunnel construction.

The seasonal distribution of rainfall (U23) affects the groundwater content. China is a vast country with diverse climates, and most areas belong to the subtropical monsoon climate with heavy rainfall in summer, leading to an increase in groundwater content and a rise in the groundwater level, which is unfavorable to the construction of the tunnel.

3.1.3. Tunnel Design (U3). The shield tunnel length (U31) affects the amount of ground loss and the time of shield excavation. The longer the tunnel, the greater the ground loss, the longer the time for shield tunneling, and the more significant the disturbance of the ground by the tunneling.

The tunnel buried depth (U32) has a large influence on tunnel stability, and the form of tunnel damage varies with the depth of buried [31]. In general, deeply buried tunnels are relatively safe as they have less impact on the ground surface during excavation than shallow buried tunnels.

The ratio of tunnel burial depth to shield diameter (U33) is an important factor affecting the stability of the tunnel surrounding rock. If the ratio is too small, it will cause undesirable phenomena such as surface subsidence and tunnel arch deformation as the stability of the surrounding rock is seriously damaged.

To meet the drainage requirements, the tunnel line is generally designed with a slope, but considering the safety of construction and the comfort of traveling, the maximum slope of the tunnel (U34) should not be too large. 
3.1.4. Shield Construction (U4). Shield tunneling can cause vibration in the surrounding strata and disrupt the initial equilibrium of the surrounding rock. The purpose of tunnel support (U41) is to reduce the vibration and maintain the stability of the tunnel. Without support, the tunnel is very likely to collapse and destabilize. Timely and reasonable support measures are an essential guarantee for the safety of tunnel construction.

The previous section of shield tunneling is regarded as the distance of shield tunneling test (U42). The test of shield tunneling has many advantages. Firstly, operators can be familiar with the mechanical properties of the shield as soon as possible. Secondly, the tunneling parameters can be adjusted and determined by analyzing shield tunneling data. Finally, during the test of shield tunneling, constructors know the impact of shield tunneling on the surrounding environment and take countermeasures by monitoring the surface settlement, underground pipelines, and buildings adjacent to the tunnel.

The shield tunneling speed (U43) which should be adjusted according to the strata traversed should not be too fast. Otherwise, it will result in serious cutting tool wear, low rock-breaking efficiency, and growth of disturbance time to the strata, which may lead to undesirable consequences such as over-excavation and surface subsidence. Therefore, the shield tunneling speed should be adjusted in time and controlled in a reasonable range.

Grouting can support the rock mass around the segment of shield, effectively control the surface subsidence, and keep the tunnel stable. At the same time, the slurry will form a waterproof layer to improve the waterproofing capacity of tunnels. It is necessary to set the proper grouting pressure
(U44) when grouting. Many factors affect the grouting pressure, such as geological conditions and grouting methods. The grouting pressure should not be too high; otherwise, the slurry overflowing into the ground will cause the ground to heave.

It is difficult to control the shield attitude when tunneling in karst strata, which makes it easy for shield to deviate from the design axis (U45), affecting the quality of tunnel construction. The shield attitude is affected by factors including power of propulsion cylinder, pressure of Earth chamber, and position of shield counterforce frame. When the shield attitude deviates, it can be corrected by adjusting the shield counterforce frame position and controlling the propulsion cylinder power, etc. The deviation should be corrected in time, for multiple times and in small amounts.

3.2. Determining the Weights of Assessment Indices. In multiindex risk assessment, the weights of indices have great influence on the risk assessment results. In this paper, the weights of each index are calculated by fuzzy analytic hierarchy process, and the process of the weight calculation is illustrated by taking the first-level indices as an example. Firstly, according to the risk assessment index system of shield tunnel construction in karst strata, three experts were invited to score the assessment indices. The scoring results are shown in Table 4.

Secondly, the triangular fuzzy number $a_{i j}$ is calculated by equations (2) and (3), and the fuzzy complementary judgment matrix $A$ of the first-level assessment indices is constructed:

$$
A=\left[\begin{array}{cccc}
(0.500,0.500,0.500) & (0.567,0.667,0.767) & (0.467,0.567,0.667) & (0.367,0.467,0.533) \\
(0.233,0.333,0.433) & (0.500,0.500,0.500) & (0.367,0.433,0.500) & (0.233,0.333,0.433) \\
(0.333,0.433,0.533) & (0.500,0.567,0.633) & (0.500,0.500,0.500) & (0.333,0.433,0.500) \\
(0.467,0.533,0.633) & (0.567,0.667,0.767) & (0.500,0.567,0.667) & (0.500,0.500,0.500)
\end{array}\right]
$$

Thirdly, the initial weights of the first-level assessment indices are obtained according to equations (4)-(6).

$$
\left\{\begin{array}{l}
\widetilde{w}_{U_{1}}=(0.210,0.275,0.356) \\
\widetilde{w}_{U_{2}}=(0.147,0.200,0.269) \\
\widetilde{w}_{U_{3}}=(0.184,0.242,0.312) \\
\widetilde{w}_{U_{4}}=(0.224,0.283,0.370)
\end{array}\right. \text {. }
$$

Fourthly, the fuzzy consistency possibility matrix is obtained by equations (7)-(10).

$$
R=\left[\begin{array}{cccc}
0.5 & 0.832 & 0.653 & 0.458 \\
0.168 & 0.5 & 0.321 & 0.126 \\
0.347 & 0.679 & 0.5 & 0.305 \\
0.542 & 0.874 & 0.695 & 0.5
\end{array}\right]
$$

Finally, the final weights of the first-level evaluation indices are obtained based on equation (11).

$$
W=\left(w_{1}, w_{2}, w_{3}, w_{4}\right)=(0.287,0.176,0.236,0.301)
$$

The final weights of all second-level assessment indices can be calculated by the same method; the calculation process is not listed in this paper. The calculated weights of all assessment indices are shown in Table 5.

3.3. Risk Assessment Model. The risk assessment indices of shield tunnel construction in karst strata are divided into two types: quantitative indices and qualitative indices. The calculation rules for cloud numerical characteristics vary in different indices. For quantitative indices, if the index has both upper and lower limits, the cloud numerical characteristics can be calculated by equation (1); if the index has 
TABLE 4: Scoring results of the experts on the first-level indices.

\begin{tabular}{lcccc}
\hline Assessment indices & Karst geological conditions & Hydrogeological conditions & Tunnel design & Shield construction \\
\hline \multirow{3}{*}{ Karst geological conditions } & & $(0.6,0.7,0.8)$ & $(0.5,0.6,0.7)$ & $(0.4,0.5,0.6)$ \\
& $(0.5,0.5,0.5)$ & $(0.6,0.7,0.8)$ & $(0.4,0.5,0.6)$ & $(0.3,0.4,0.5)$ \\
& & $(0.5,0.6,0.7)$ & $(0.5,0.6,0.7)$ & $(0.4,0.5,0.5)$ \\
\hline \multirow{3}{*}{ Hydrogeological conditions } & $(0.2,0.3,0.4)$ & & $(0.4,0.4,0.5)$ & $(0.3,0.4,0.5)$ \\
& $(0.2,0.3,0.4)$ & $(0.5,0.5,0.5)$ & $(0.3,0.4,0.5)$ & $(0.2,0.3,0.4)$ \\
& $(0.3,0.4,0.5)$ & & $(0.4,0.5,0.5)$ & $(0.2,0.3,0.4)$ \\
\hline \multirow{3}{*}{ Tunnel design } & $(0.3,0.4,0.5)$ & $(0.5,0.6,0.6)$ & $(0.3,0.4,0.5)$ \\
& $(0.4,0.5,0.6)$ & $(0.5,0.6,0.7)$ & $(0.5,0.5,0.5)$ & $(0.4,0.4,0.5)$ \\
Shield construction & $(0.3,0.4,0.5)$ & $(0.5,0.5,0.6)$ & $(0.5,0.5)$ \\
& $(0.4,0.5,0.6)$ & $(0.5,0.6,0.7)$ & $(0.5,0.6,0.7)$ & $(0.5,0.6,0.7)$ \\
\end{tabular}

TABLE 5: Weights of risk assessment indices.

\begin{tabular}{|c|c|c|c|}
\hline First-level assessment indices & Weights & Second-level assessment indices & Weights \\
\hline \multirow{5}{*}{ Karst geological conditions } & \multirow{5}{*}{0.287} & Karst distribution characteristics & 0.184 \\
\hline & & Degree of karst development & 0.248 \\
\hline & & Scale of cave development & 0.201 \\
\hline & & Stability of the cave roof & 0.206 \\
\hline & & Cave filling situation & 0.161 \\
\hline \multirow{3}{*}{ Hydrogeological conditions } & \multirow{3}{*}{0.176} & Groundwater level & 0.451 \\
\hline & & Underground water richness & 0.318 \\
\hline & & Seasonal distribution of rainfall & 0.231 \\
\hline \multirow{4}{*}{ Tunnel design } & \multirow{4}{*}{0.236} & Shield tunnel length & 0.195 \\
\hline & & Tunnel buried depth & 0.296 \\
\hline & & Ratio of tunnel burial depth to shield diameter & 0.311 \\
\hline & & Maximum slope of tunnel & 0.198 \\
\hline \multirow{5}{*}{ Shield construction } & \multirow{5}{*}{0.301} & Tunnel support & 0.233 \\
\hline & & Distance of shield tunneling test & 0.154 \\
\hline & & Shield tunneling speed & 0.184 \\
\hline & & Grouting pressure & 0.197 \\
\hline & & Distance of shield deviation from design axis & 0.232 \\
\hline
\end{tabular}

only upper or lower limit, the cloud numerical characteristics can be determined from the boundary value. For instance, if the risk level is divided into four intervals, I $(0, a)$, II $(a, b)$, III $(b, c)$, and IV $(c,+\infty)$, the calculation rules for the cloud numerical characteristics are shown in Table 6.

Quantitative indices that have different dimensions and magnitudes cannot be directly compared and thus need to be standardized. The assessment indices are divided into positive indices (the larger the value, the greater the risk) and negative indices (the smaller the value, the greater the risk), and the standardization process differs between these two types of indices [32].

Positive indices:

$$
\bar{r}_{i j}=\frac{r_{i j}-\min _{j}\left(r_{i j}\right)}{\max _{j}\left(r_{i j}\right)-\min _{j}\left(r_{i j}\right)} .
$$

Negative indices

$$
\bar{r}_{i j}=\frac{\max _{j}\left(r_{i j}\right)-r_{i j}}{\max _{j}\left(r_{i j}\right)-\min _{j}\left(r_{i j}\right)},
$$

TABLE 6: Calculation rules for cloud numerical characteristic of quantitative indices.

\begin{tabular}{lccc}
\hline Risk level & $E x$ & $E n$ & $H e$ \\
\hline I & $E x_{1}=(0+a) / 2$ & $E_{n 1}=(a-0) / 6$ & 0.01 \\
II & $E x_{2}=(a+b) / 2$ & $E_{n 2}=(b-a) / 6$ & 0.01 \\
III & $E x_{3}=(b+c) / 2$ & $E_{n 3}=(c-b) / 6$ & 0.01 \\
IV & $E x_{4}=c$ & $E_{n 4}=E_{n 3}$ & 0.01 \\
\hline
\end{tabular}

where $r_{i j}$ is the value before standardization and $r_{i j}$ is the value after standardization.

Qualitative indices for values that cannot be determined should be quantified by expert scoring. The process of expert scoring is as follows, $m$ experts are invited to score the evaluation indexes according to the actual engineering situation, letting the score of expert $n$ be $x_{n}$, so that the cloud numerical characteristics ( $E x, E n$, and $H e$ ) of the qualitative indices can be calculated by backward cloud generator. The calculation process is shown in the following equation: 


$$
\left\{E x=\frac{1}{m} \sum_{n=1}^{m} x_{n}, E n=\sqrt{\frac{\pi}{2}} \times \frac{1}{m} \sum_{n=1}^{m}\left|x_{n}-E x\right|, S^{2}=\frac{1}{m-1} \sum_{n=1}^{m}\left(x_{n}-E x\right)^{2}, H e=\sqrt{s^{2}-E n^{2}},\right.
$$

where $S^{2}$ is the sample variance.

After obtaining the cloud model numerical characteristics of all the second-level indices, it is also necessary to calculate the cloud numerical characteristics of the first-level indices as well as the comprehensive cloud numerical characteristics. Equation (19) can be used to transform the numerical characteristics of the underlying indices into upper level ones, and the calculation process is as follows:

$$
\left\{\begin{array}{l}
E x=\frac{\sum_{i=1}^{t} E x_{i} E n_{i} w_{i}}{\sum_{i=1}^{t} E n_{i} w_{i}}, \\
E n=\sum_{i=1}^{t} E n_{i} w_{i}, \\
H e=\frac{\sum_{i=1}^{t} H e_{i} E n_{i} w_{i}}{\sum_{i=1}^{n} E n_{i} w_{i}},
\end{array}\right.
$$

where $E x_{i}, E n_{i}, H e_{i}$, and $w_{i}$ are the expectation, entropy, hyper entropy, and weight of the underlying indices, respectively, and $t$ denotes the number of underlying indices corresponding to the upper level indices.

After obtaining the cloud numerical characteristics, the MATLAB software is used to edit the forward-normal cloud generator, and the calculated cloud numerical characteristics are substituted into the cloud generator to generate standard cloud diagram and risk cloud diagram. The risk level of the evaluation object is determined preliminarily by observing the position of the risk cloud in the standard cloud.

The preliminary determination of the risk level should be validated. The validation method is as follows: the certainty degrees of the index $X$ for each risk level are calculated by equation (19), and then the risk level corresponding to this index is determined according to the principle of maximum certainty, and finally the risk level is compared with the results of the risk assessment model based on FAHP and cloud model theory to verify the accuracy of this risk assessment model [33].

$$
\mu_{j}=e^{-\left(x-E_{x}\right)^{2} / 2 E_{n}^{\prime 2}},
$$

where $\mu_{j}$ is the certainty degree of the assessment index for the $j$ th risk level, $x$ is a variable and obeys the Gaussian distribution $x \sim N\left(E x, E n^{\prime 2}\right), E x$ is the expectation, and $E n^{\prime}$ is the entropy and obeys the Gaussian distribution $E n^{\prime} \sim N\left(E n, H e^{2}\right)$.

\section{Engineering Applications}

4.1. Project Overview. Located in the south of China, Liuzhou is an essential transportation hub. Liuzhou has a subtropical monsoon climate with cold and dry winters, and hot and rainy summers. The rainy season is concentrated between April and September, when more than $70 \%$ of the annual rainfall falls. According to the statistics of meteorological stations, the average rainfall and evaporation in Liuzhou City by month from 1961 to 2015 are shown in Figure 5. Liuzhou Rail Transit Line 1 is the first rail transit launched for construction in Liuzhou City. The interval from Shuanglong Station to Hedong Junction Station is constructed by the shield method. The shield diameter is $6.7 \mathrm{~m}$, the tunnel length is about $794.2 \mathrm{~m}$, the tunnel maximum burial depth is about $19 \mathrm{~m}$, and the maximum longitudinal slope is $20.5 \%$. The project location of the tunnel interval between Shuanglong Station and Hedong Junction Station is shown in Figure 6. The interval belongs to plain terrain, with gentle topography and small relative height difference, and the ground elevation is $88.28-91.16 \mathrm{~m}$. Within the tunnel interval, mainly the Quaternary stratum and Carboniferous stratum are present. The surface is the Quaternary artificial fill layer, which is mainly fill soil composed of clay, gravel, concrete blocks, etc. Downward are the silty clay of the Quaternary lake deposit, the red clay of the Quaternary eluvium, and the dolomite of the Carboniferous Middle Huanglong Formation, respectively. The values of three indicators reflecting the characteristics of karst development (hole-bore percentage, line karst rate, and units-inflow of drilling) are $45.99 \%, 14.68 \%$, and $2.139 \mathrm{~L} /(\mathrm{s}-\mathrm{m})$, respectively, and the karst development is strongly developed according to the classification of the degree of karst development. The caves are mainly fully filled, with a few empty caves, and the distribution of caves is irregular and inhomogeneous. The treatment of karst caves is to first drill holes with a downthe-hole drill and then grout with sleeve valve tubes. Figure 7 shows the process of drilling with a down-the-hole drill. The groundwater types are mainly upper perched water and carbonate rock caves water and the amount of water is abundant. The overlying soil of the tunnel is filling soil and red clay, and the lower part is mainly weathered dolomite where karst is developed, which is not conducive for shield tunneling, and problems such as surface subsidence and tunnel water inrush may occur during tunnel construction. The geological cross section of the tunnel at DK21 +510 is shown in Figure 8.

\subsection{Risk Assessment Process}

\subsubsection{Calculating Cloud Numerical Characteristics.} According to the risk assessment system of shield tunnel construction in karst strata, for quantitative indices, the values are determined based on the actual situation of the project, and the averages are taken if the actual value is an interval, as shown in Table 7. Then the data are standardized by equations (16) and (17), and the cloud numerical characteristics of quantitative indices are obtained according to the calculation rules of equation (1) and Table 1 . In addition, the qualitative indices are quantified by the expert scoring, 


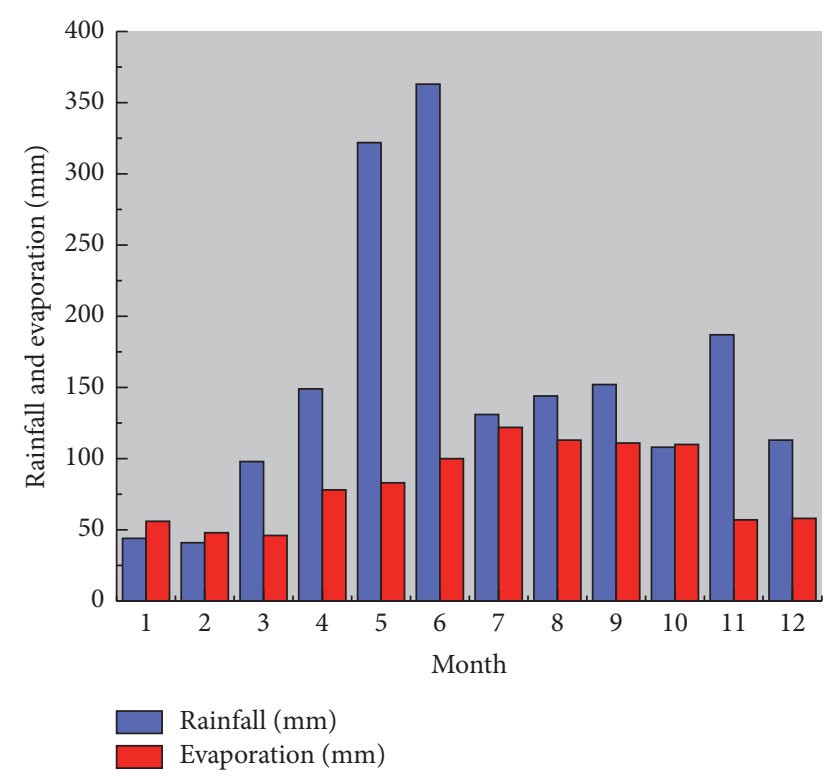

FIGURE 5: Monthly average rainfall and evaporation in Liuzhou.

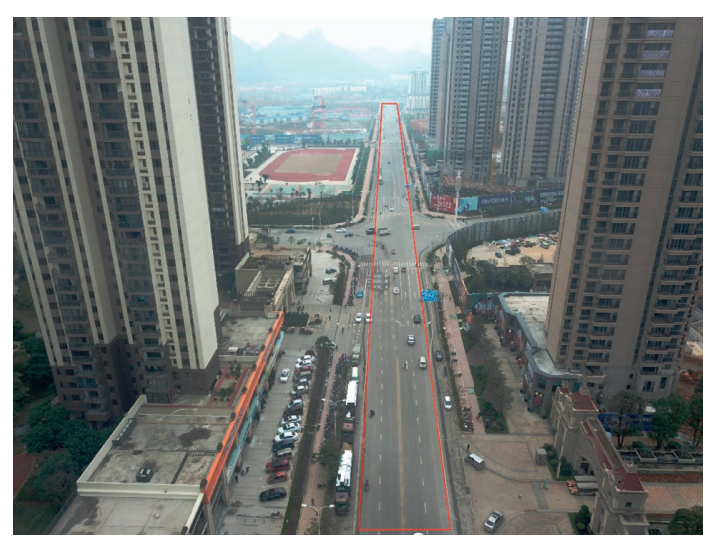

FIGURE 6: The project location of the tunnel interval.

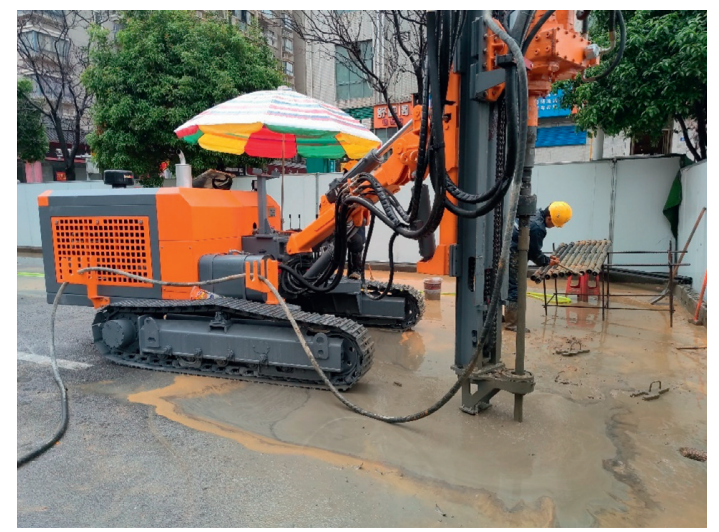

FIGURE 7: Karst cave grouting.

the scoring results are shown in Table 8 , and then the numerical characteristics of these indices are calculated via the backward cloud generator. Integrating the calculation results of the quantitative and qualitative indices, the cloud numerical characteristics of all evaluation indices can be obtained, as shown in Table 9.

The cloud numerical characteristics of the second-level indices in Table 9 are substituted into equation (19) to calculate the cloud numerical characteristics of the four firstlevel indices: V1 $(0.625,0.034,0.01)$, V2 $(0.571,0.043,0.01)$, V3 (0.248, 0.068, 0.01), and V4 (0.387, 0.100, 0.01). According to the cloud numerical characteristics of the four first-level indices, the comprehensive cloud numerical characteristic V $(0.410,0.063,0.01)$ can be obtained.

4.2.2. Risk Assessment Results. According to the calculation results of the cloud numerical characteristics, the forward normal cloud generator is used to generate the comprehensive risk cloud and the standard risk cloud of shield construction tunnel in karst strata. The comprehensive risk cloud and the standard risk cloud are combined to form a comprehensive risk cloud diagram, as shown in Figure 9. In order to observe the risk status of karst geological conditions in the project, a U1 risk cloud diagram is generated, as shown in Figure 10. The risk level can be initially determined by observing the position of the risk cloud in the standard risk cloud.

As can be seen from Figure 9, the comprehensive risk cloud drops mainly fall between level II (moderate risk) and level III (high risk), and level II risk accounts for a larger proportion. Therefore, it is initially determined that the comprehensive risk level of shield tunnel construction in karst strata is level II. To verify the accuracy of the risk assessment result, the certainty degrees of the comprehensive risk for each risk level are calculated by equation (20), and the calculation results are $\mu_{1}=0.003, \mu_{2}=0.327$, $\mu_{3}=0.029$, and $\mu_{4}=0 . \mu_{2}>\mu_{3}>\mu_{1}>\mu_{4}$; hence, when $j=2$, the certainty degree is the largest. According to the principle of maximum certainty, the comprehensive risk level is II, which is consistent with the results of comprehensive risk cloud diagram. In addition, the assessment result was compared with those of the fuzzy comprehensive evaluation method, the set pair analysis, and the extension theory (see Table 10). It can be found that the assessment results of these methods are consistent, indicating that it is feasible to apply the risk assessment model based on FAHP-cloud model to the risk assessment of shield tunnel construction in karst strata.

As shown in Figure 10, the vast majority of $\mathrm{U} 1$ risk cloud drops fall within the range of level III, so the preliminary judgment of the risk level of karst geological conditions is level III. Similarly, the certainty degrees of U1 risk for each risk level are calculated by equation (20), and the results are $\mu_{1}=0, \mu_{2}=0.027, \mu_{3}=0.623$, and $\mu_{4}=0.035$. Obviously, the certainty degree is maximum when $j=3$. According to the principle of maximum certainty, the risk level of U1 is III, in line with the results of U1 risk cloud diagram. The high risk level of karst geological conditions is attributed to the strongly developed, irregular, and uneven distribution of karst within the study area and the poor stability of karst caves, which makes cave treatment difficult and poses a serious threat to the safety of staff. Therefore, the treatment of karst is 


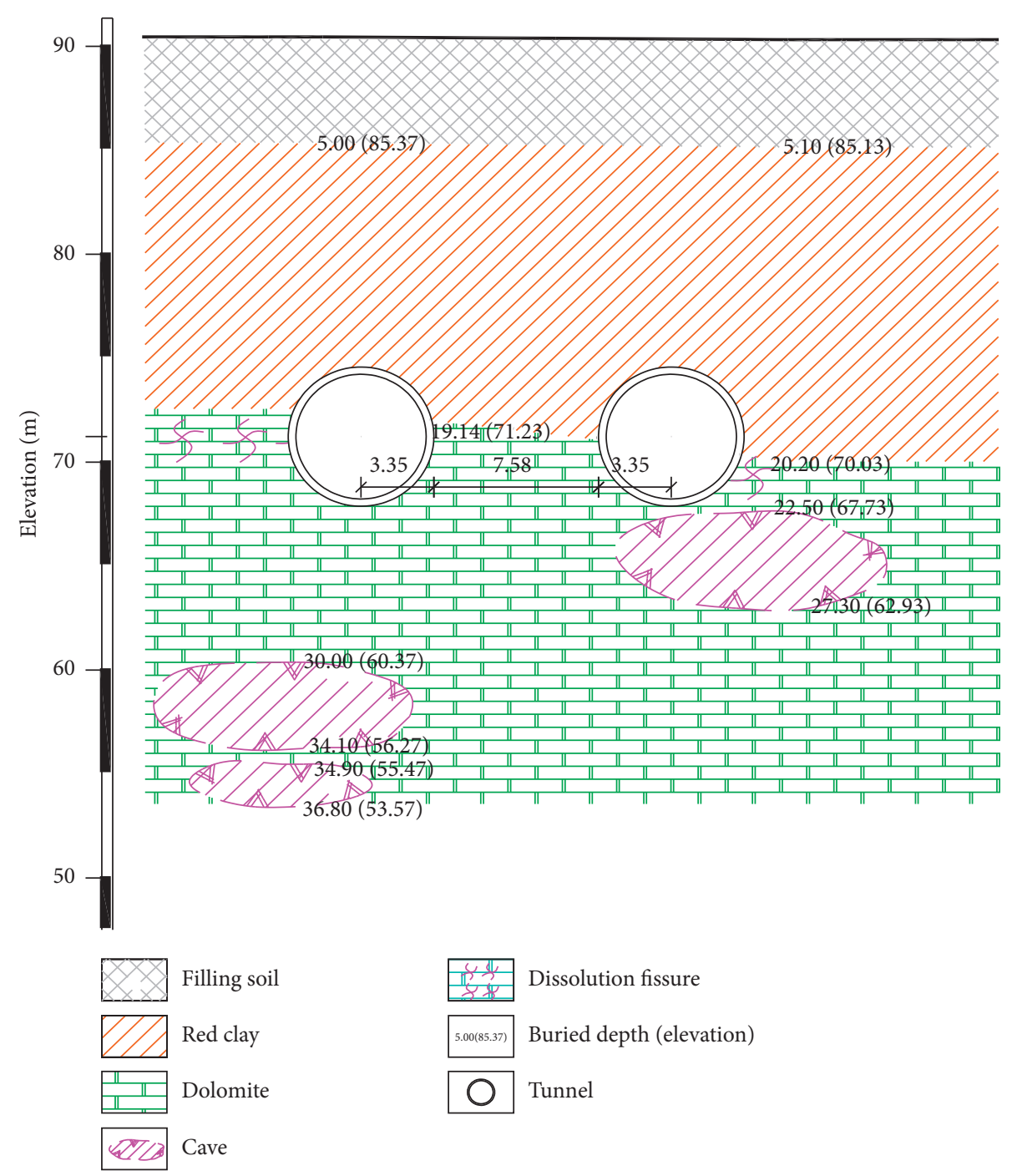

Figure 8: Tunnel geological cross section.

TABLE 7: Actual values of quantitative indices.

\begin{tabular}{lcccccccccc}
\hline Quantitative indices & $\mathrm{U} 13(\mathrm{~m})$ & $\mathrm{U} 21(\mathrm{~m})$ & $\mathrm{U} 31(\mathrm{~m})$ & $\mathrm{U} 32(\mathrm{~m})$ & $\mathrm{U} 33$ & $\mathrm{U} 34$ & $\mathrm{U} 42(\mathrm{~m})$ & $\mathrm{U} 43$ & $\mathrm{U} 44(\mathrm{MPa})$ & $\mathrm{U} 45(\mathrm{~mm})$ \\
\hline Actual values & 4.25 & 17.8 & 794 & 16.5 & 2.35 & $20.5 \% 0$ & 100 & 8 Loops/day & 0.33 & 18.2 \\
\hline
\end{tabular}

TABLE 8: Scoring results of qualitative indices.

\begin{tabular}{lcccccccc}
\hline \multirow{2}{*}{ Qualitative indices } & \multicolumn{8}{c}{ Experts } \\
& $\mathrm{A}$ & $\mathrm{B}$ & $\mathrm{C}$ & $\mathrm{D}$ & $\mathrm{E}$ & $\mathrm{F}$ & $\mathrm{H}$ & $\mathrm{I}$ \\
\hline $\mathrm{U} 11$ & 0.80 & 0.88 & 0.78 & 0.93 & 0.83 & 0.80 & 0.86 & 0.85 \\
U12 & 0.85 & 0.76 & 0.86 & 0.85 & 0.90 & 0.82 & 0.78 & 0.82 \\
U14 & 0.38 & 0.33 & 0.37 & 0.35 & 0.36 & 0.40 & 0.36 & 0.35 \\
U15 & 0.18 & 0.17 & 0.15 & 0.18 & 0.15 & 0.20 & 0.21 & 0.18 \\
U22 & 0.78 & 0.85 & 0.85 & 0.82 & 0.76 & 0.87 & 0.80 & 0.78 \\
U23 & 0.63 & 0.56 & 0.58 & 0.65 & 0.62 & 0.66 & 0.65 & 0.55 \\
U41 & 0.35 & 0.33 & 0.42 & 0.45 & 0.35 & 0.46 & 0.38 & 0.4 \\
\hline
\end{tabular}

the key to safe construction of the tunnel. The karst caves in this project are treated by drilling with a down-the-hole drill and then grouting with sleeve valve tubes. The process of grouting is as follows: measuring unreeling-drilling-placing grouting tubes-pouring shell material-grouting-the first grouting meets the requirements-the second grouting-meeting the requirements-ending grouting. The principles of caves grouting are: (1) each hole should be grouted at least twice; (2) the grouting amount needs to exceed the estimated amount; (3) the grouting pressure should be gradually increased to the design final pressure of $2 \mathrm{MPa}$, and the grouting should be continuous for more than $10 \mathrm{~min}$; (4) the speed at the end of grouting is less than $5 \mathrm{~L} / \mathrm{min}$.

4.3. Excavation Verification. The tunnel excavation process was carried out in accordance with the construction scheme, and the interval from Shuanglong Station to Hedong Junction Station in the left tunnel has now been completed. During the shield tunnel construction, there appeared 
TABLE 9: Cloud numerical characteristics of all evaluation indices.

\begin{tabular}{lccc}
\hline Assessment indices & Cloud numerical characteristics & Assessment indices & Cloud numerical characteristics \\
\hline U11 & $(0.841,0.049,0.01)$ & $\mathrm{U} 12$ & $(0.83,0.044,0.01)$ \\
U13 & $(0.4,0.033,0.01)$ & $\mathrm{U} 14$ & $(0.363,0.02,0.02)$ \\
U15 & $(0.178,0.02,0.01)$ & $\mathrm{U} 21$ & $(0.375,0.042,0.01)$ \\
U22 & $(0.814,0.042,0.01)$ & $\mathrm{U} 23$ & $(0.613,0.046,0.02)$ \\
U31 & $(0.25,0.028,0.01)$ & $\mathrm{U} 32$ & $(0.25,0.083,0.01)$ \\
U33 & $(0.167,0.056,0.01)$ & $\mathrm{U} 34$ & $(0.313,0.104,0.01)$ \\
U41 & $(0.393,0.05,0.01)$ & $\mathrm{U} 42$ & $(0.5,0.056,0.01)$ \\
U43 & $(0.375,0.042,0.01)$ & $\mathrm{U} 44$ & $(0.344,0.075,0.01)$ \\
U45 & $(0.4,0.067,0.01)$ & & \\
\hline
\end{tabular}

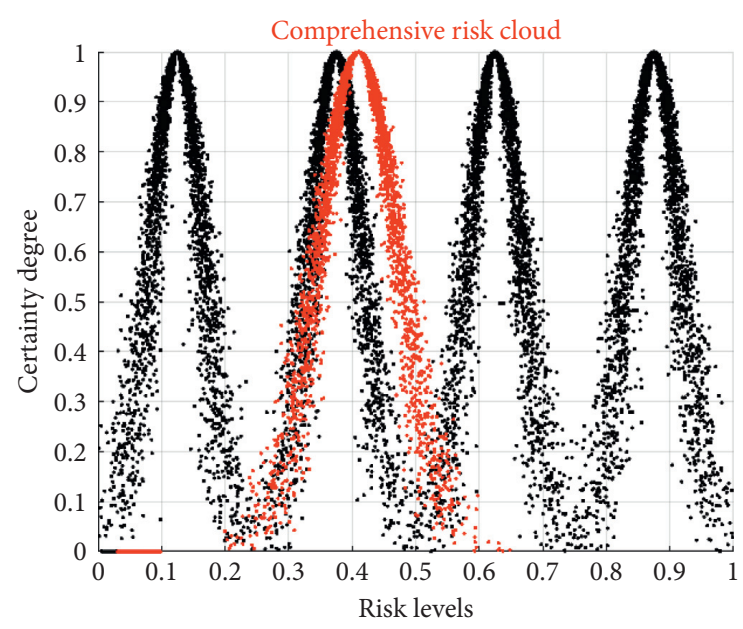

Figure 9: Comprehensive risk cloud diagram.

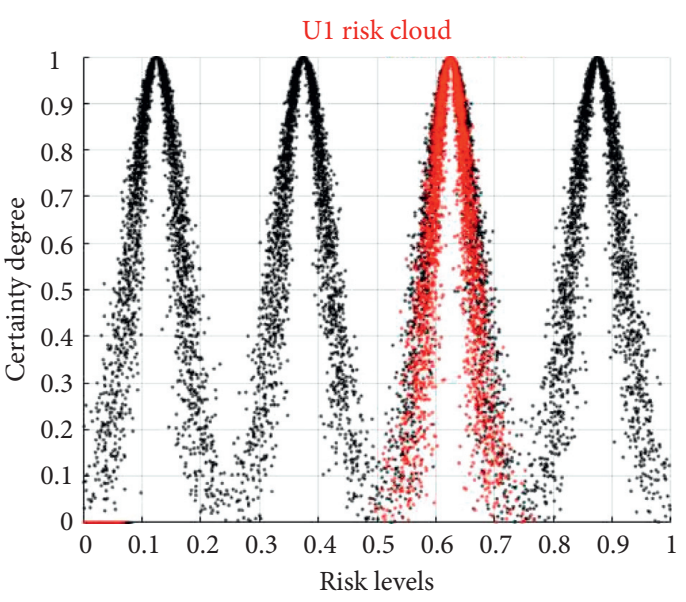

FIGURE 10: U1 risk cloud diagram.

undesirable phenomena such as slight water seepage on the excavation surface (Figure 11(a)), water gushing out from the dewatering wells of the station (Figure 11(b)), clay clogging in shield cutter-head (Figure 11(c)), and severe tool wear (Figure 11(d)).

The causes of these undesirable phenomena and the measures to deal with them are described next. The reasons for the slight water seepage at the excavation surface are the high groundwater level, the uneven vertical stratigraphy, and the poor effect of the water-resisting curtain. Since the excavation surface is only slightly seeping, no sand gushing phenomenon occurs, and the soil around the station is dense and the enclosure structure is intact, it will not have a large impact on the main structure of the station and the surrounding buildings, and it does not get worse in the followup observation, so there is no need to take treatment measures.

Cause of water gushing out from the dewatering wells of the station: the location is rich in groundwater, with many days of continuous heavy rain, resulting in water gushing out from the dewatering wells. Treatment measures are to replace the high power pump for pumping, and then to plug the dewatering wells.

The reasons of clay clogging in shield cutter-head: the clay content of soil in karst strata, red clay strata, and strongly weathered dolomite strata is large, and it is easy to cause clay clogging in the cutter-head if the sediment is not well improved during the shield tunneling process. The treatment measure is to add an appropriate amount of soil improver during the excavation process for improving the workability of soil.

The reason for severe tool wear is that it is difficult to break rocks when the shield passes through the upper soft and lower hard strata (red clay strata and karst strata in the upper part, and dolomite strata in the lower part), and the tools are easily damaged abnormally by the impact. Measures: The cutting edge of the tool is made of special high-quality tool steel to enhance wear resistance, and two hydraulic wear detection knives are installed on the spokes of the cutter disc to detect tool wear. Furthermore, the damaged tools should be replaced in time if they are found during the tunneling process, and the tools should be checked and replaced frequently.

Although the above undesirable phenomena occurred during the construction process, they were easy to solve and generally did not have a serious impact on the project. Moreover, there were no serious accidents such as tunnel collapse, water inrush, and surface subsidence that could lead to significant economic losses or casualties. Consequently, the risk level of the project is moderate in terms of the damage caused.

To observe the vertical displacement of the ground surface during shield tunneling, five monitoring points BDZ21372-4, BDZ21375, BDZ21380-4, BDZ213854, and BDZ21390-4 in the left tunnel were selected for monitoring. The location of partial 
TABLE 10: Result comparison of the FAHP-cloud model with other methods.

\begin{tabular}{lcccc}
\hline Assessment methods & FAHP-cloud model & Fuzzy comprehensive evaluation method & Set pair analysis & Extension theory \\
\hline Assessment results & II & II & II & II \\
\hline
\end{tabular}
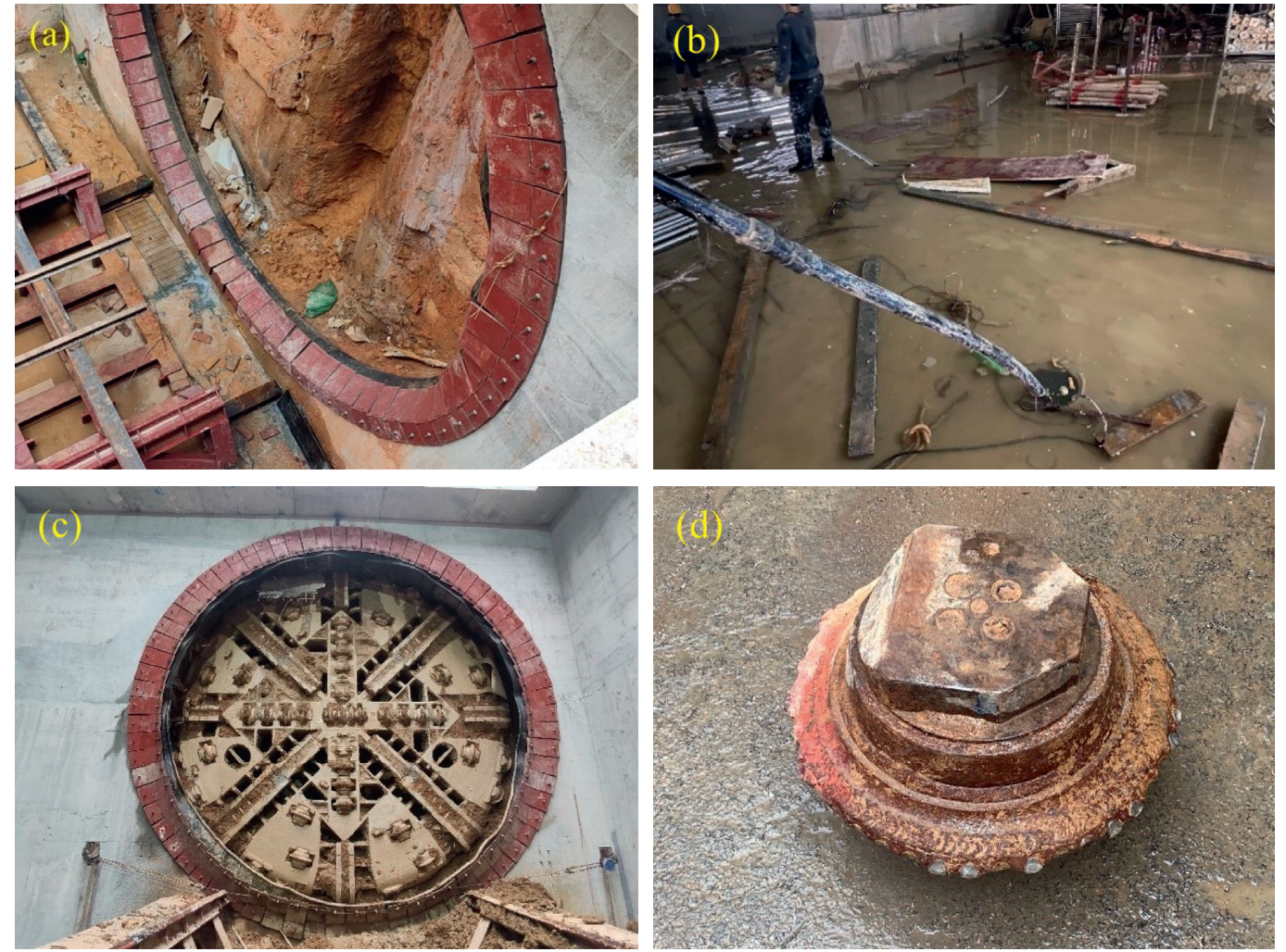

FIgUre 11: Actual excavation situation.

monitoring points in the Shuanglong Station-Hedong Junction Station interval is shown in Figure 12. The surface vertical displacements monitored at these five monitoring points from August 5, 2020, to September 15, 2020, are shown in Figure 13, with the down curve indicating surface subsidence and up curve indicating surface heave. As can be seen in Figure 13, As can be seen from Figure 13, the ground surface settled during the period, and the maximum cumulative settlement value was $15.63 \mathrm{~mm}$, which did not reach the warning value. However, the change rate of vertical displacement at monitoring point DBZ21390-4 on August 30 was $-3.1 \mathrm{~mm} /$ day, which exceeded the control value owing to the excessive speed of shield excavation on that day and the failure to carry out synchronous grouting and secondary grouting in time. The change rate of vertical displacement at monitoring point DBZ21380-4 was $3.2 \mathrm{~mm} /$ day on August 25, which also exceeded the control value, as well as the surface heave from September 7 to September 11 . These were caused by the grouting reinforcement of the right tunnel, rather than by the shield tunneling in the left line. After September 13, the vertical displacement of the ground surface tends to stabilize.
According to the above analysis, the interval from Shuanglong Station to Hedong Junction Station of Liuzhou Rail Transit Line 1 left tunnel is at moderate risk, which is consistent with the assessment results of the proposed risk assessment model, verifying the accuracy and reliability of the risk assessment method.

The risk of shield tunneling in karst strata is a qualitative concept, which is influenced by several factors (such as karst geological conditions, hydrogeological conditions, tunnel design factors, and shield construction factors) and has a strong randomness and fuzziness, so it is difficult to assess risk. Cloud model theory interconverts cloud droplets and numerical characteristics via cloud generators to achieve a quantitative representation of qualitative concepts. In this paper, the quantitative values calculated by the forward normal cloud generator are used to characterize the randomness and fuzziness of the construction risk of shield tunnel in karst strata. The study demonstrates that the comprehensive risk level of shield construction in karst strata is II (moderate risk), and in order to ensure construction safety, monitoring and management need to be strengthened. 


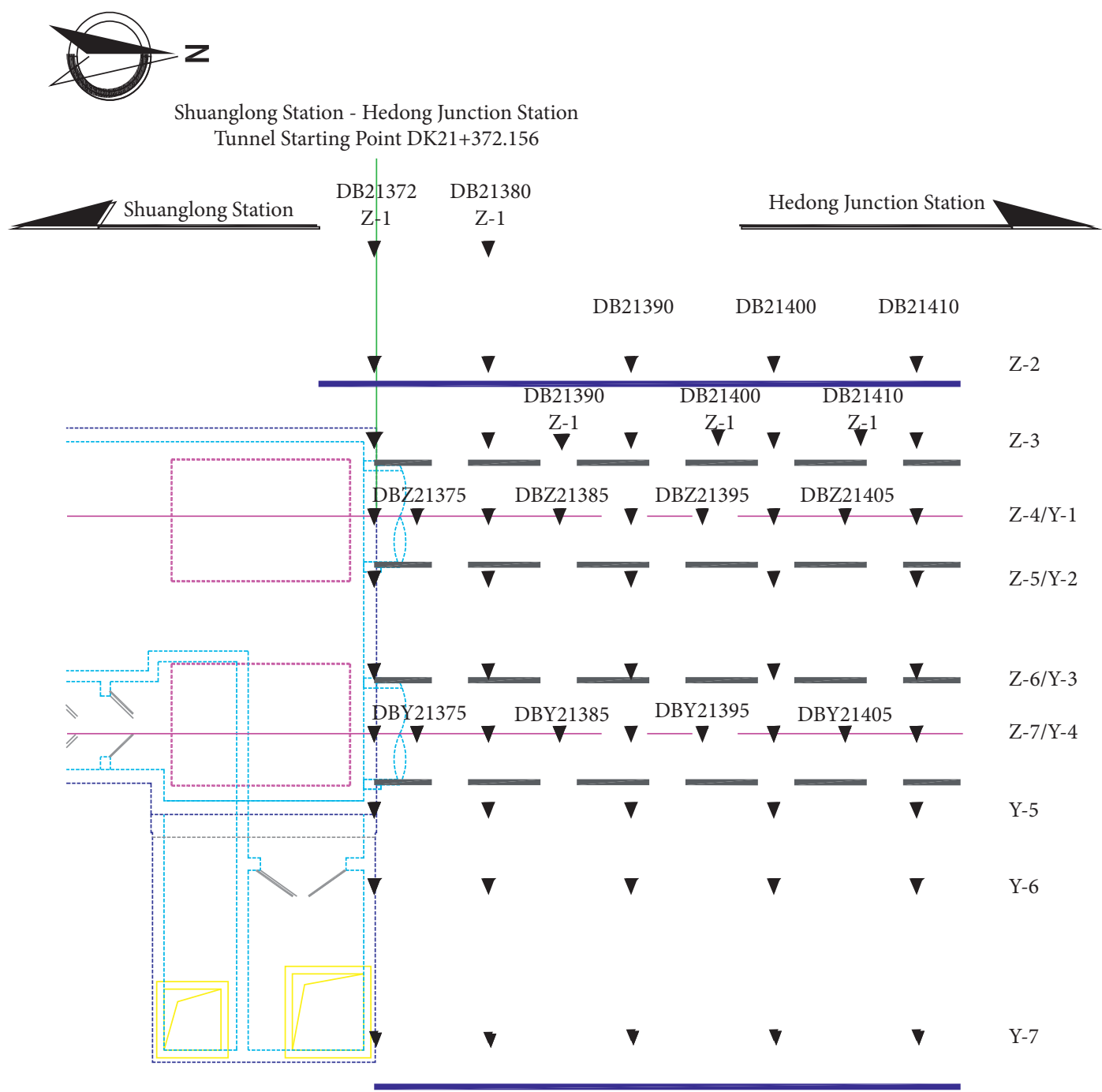

FIgURE 12: The location of partial monitoring points.

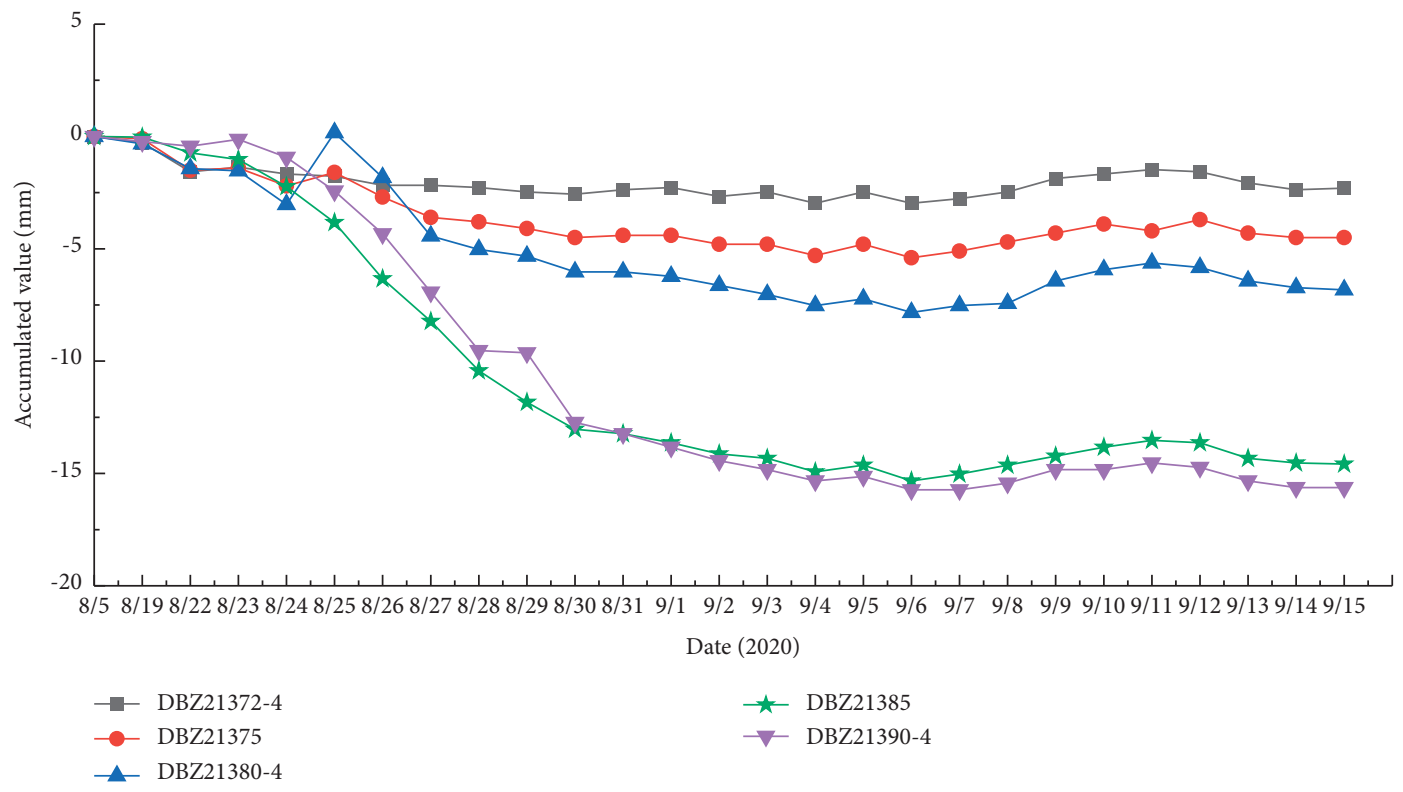

FIgURE 13: Curve of ground surface vertical displacement. 


\section{Conclusion}

For the complexity, fuzziness, and randomness of shield tunneling in karst strata, a risk assessment model based on cloud model theory and fuzzy analytic hierarchy process is proposed:

(1) A risk assessment index system including four firstlevel indices and seventeen second-level indices and the corresponding risk level classification criteria have been constructed to fully reflect the factors affecting tunnel construction safety. FAHP is used to determine the index weights, and cloud model theory is used to calculate the cloud numerical characteristics of each index and generate the risk cloud diagram. Then, the certainty degrees of the assessment objects corresponding to each risk level are calculated, and the final risk level is determined by the risk cloud diagram and the principle of maximum certainty.

(2) Applying the risk assessment model to the risk analysis and calculation of shield tunnel engineering, a comprehensive risk level of II (moderate risk) which matches well with the actual excavation of the tunnel is obtained. It demonstrates that the risk assessment model has high accuracy and reliability so that it can be used as a reference for shield tunnel construction in karst strata.

(3) The application of risk assessment model based on FAHP and cloud model theory to the project of shield tunnel construction in karst strata is only a preliminary attempt, and many issues need to be further explored. For instance, the cloud model used now is just a one-dimensional cloud model, and it is of great study significance to apply the two-dimensional or multi-dimensional cloud model to the risk assessment of shield construction in karst strata.

\section{Data Availability}

The data used to support the findings of this study are available from the corresponding author upon request.

\section{Conflicts of Interest}

The authors declare that they have no conflicts of interest.

\section{Acknowledgments}

The authors would like to appreciate the financial support from the National Natural Science Foundation of China (Grant nos. 51678164 and 51478118), the Guangxi Natural Science Foundation Program (2018GXNSFDA138009), and the Scientific Research Foundation of Guangxi University (No. XTZ160590).

\section{References}

[1] S.-C. Li, Z.-Q. Zhou, L.-P. Li, Z.-H. Xu, Q.-Q. Zhang, and S.-S. Shi, "Risk assessment of water inrush in karst tunnels based on attribute synthetic evaluation system," Tunnelling and Underground Space Technology, vol. 38, pp. 50-58, 2013.
[2] X. T. Wang, S. C. Li, Z. H. Xu, X. Z. Li, and P. Lin, “An interval risk assessment method and management of water inflow and inrush in course of karst tunnel excavation," Tunnelling and Underground Space Technology incorporating Trenchless Technology Research, vol. 92, Article ID 103033, 2019.

[3] H. Chu, G. Xu, N. Yasufuku, Z. Yu, P. Liu, and J. Wang, "Risk assessment of water inrush in karst tunnels based on two-class fuzzy comprehensive evaluation method," Arabian Journal of Geosciences, vol. 10, no. 7, pp. 179-190, 2017.

[4] J. S. Xu, H. Xu, R. F. Sun, X.-W. Zhao, and Y. Cheng, "Seismic risk evaluation for a planning mountain tunnel using improved analytical hierarchy process based on extension theory," Journal of Mountain Science, vol. 17, no. 3, pp. 244-260, 2020.

[5] Z. Li, Y. Wang, C. G. Olgun, S. Yang, Q. Jiao, and M. Wang, "Risk assessment of water inrush caused by karst cave in tunnels based on reliability and GA-BP neural network," Geomatics, Natural Hazards and Risk, vol. 11, no. 1, pp. 1212-1232, 2020.

[6] Y. Wang, H. Jing, L. Yu, H. Su, and N. Luo, "Set pair analysis for risk assessment of water inrush in karst tunnels," Bulletin of Engineering Geology and the Environment, vol. 76, no. 3, pp. 1199-1207, 2017.

[7] L. Y. Huang, J. S. Yang, C. Zhang, C. Jiang, and B. Z. Su, "Prediction and analysis of shield tunneling parameters in underwater karst stratum based on BP neural network," China Civil Engineering Journal, vol. 53, no. s1, pp. 75-80+98, 2020.

[8] Y. Zhao, H. L. Fu, Y. Shi, Y. Jiang, and H. Tian, "Risk level analysis of large diameter shield tunneling through karst area at river bottom," Journal of China \& Foreign Highway, vol. 38, no. 4, pp. 212-217, 2018.

[9] Y. Y. Zhou, Y. T. He, J. L. Zhao, Q. Z. Zhang, and Q. Pan, "Safety analysis of shield tunnel construction in karst area based on Bayesian network," Modern Tunnelling Technology, vol. 55, no. s2, pp. 764-771, 2018.

[10] H. M. Lyu, S. L. Shen, A. N. Zhou, and W. H. Zhou, "Flood risk assessment of metro systems in a subsiding environment using the interval FAHP-FCA approach," Sustainable Cities and Society, vol. 50, Article ID 101682, 2019.

[11] H. M. Lyu, W. H. Zhou, S. L. Shen, and A. N. Zhou, "Inundation risk assessment of metro system using AHP and TFN-AHP in Shenzhen," Sustainable Cities and Society, vol. 56, Article ID 102103, 2020.

[12] H.-M. Lyu, W.-J. Sun, S.-L. Shen, and A. Arulrajah, "Flood risk assessment in metro systems of mega-cities using a GISbased modeling approach," The Science of the Total Environment, vol. 626, pp. 1012-1025, 2018.

[13] H. M. Lyu, S. L. Shen, A. N. Zhou, and J. Zhou, "Risk assessment of mega-city infrastructures related to land subsidence using improved trapezoidal FAHP," The Science of the Total Environment, vol. 717, Article ID 135310, 2020.

[14] D. Y. Li, H. J. Meng, and X. M. Shi, "Membership cloud and membership cloud generators," Journal of Computer Research and Development, vol. 6, pp. 15-20, 1995.

[15] D. Y. Li, "Uncertainty in knowledge representation," Strategic Study of CAE, vol. 10, pp. 73-79, 2000.

[16] Z. Q. Li, Y. G. Xue, S. C. Li et al., "Rock burst risk assessment in deep-buried underground caverns: a novel analysis method," Arabian Journal of Geosciences, vol. 13, no. 11, pp. 86-95, 2020.

[17] Z. Huang, H. L. Fu, J. B. Zhang, W. Chen, and Y. Shi, "Structural damage evaluation method for metro shield tunnel," Journal of Performance of Constructed Facilities, vol. 33, no. 1, Article ID 0001248, 2019. 
[18] X. Wang, S. Li, Z. Xu, J. Hu, D. Pan, and Y. Xue, "Risk assessment of water inrush in karst tunnels excavation based on normal cloud model," Bulletin of Engineering Geology and the Environment, vol. 78, no. 5, pp. 3783-3798, 2019.

[19] Y. Peng, L. Wu, Q. Zuo, C. Chen, and Y. Hao, "Risk assessment of water inrush in tunnel through water-rich fault based on AHP-Cloud model," Geomatics, Natural Hazards and Risk, vol. 11, no. 1, pp. 301-317, 2020.

[20] X. Wang, K. Shi, Q. Shi, H. Dong, and M. Chen, "A normal cloud model-based method for risk assessment of water inrush and its application in a super-long tunnel constructed by a tunnel boring machine in the arid area of northwest China," Water, vol. 12, no. 3, pp. 644-663, 2020.

[21] C. J. Lin, M. Zhang, Z. Q. Zhou et al., "A new quantitative method for risk assessment of water inrush in karst tunnels based on variable weight function and improved cloud model," Tunnelling and Underground Space Technology incorporating Trenchless Technology Research, vol. 95, Article ID 103136, 2020.

[22] C. J. Lin, M. Zhang, L. P. Li et al., "Risk assessment of tunnel construction based on improved cloud model," Journal of Performance of Constructed Facilities, vol. 34, no. 3, Article ID 0001421, 2020.

[23] H. M. Lyu, W. J. Sun, S. L. Shen, and A. N. Zhou, "Risk assessment using a new consulting process in fuzzy AHP," Journal of Construction Engineering and Management, vol. 146, no. 3, Article ID 0001757, 2020.

[24] D. Y. Lin, M. F. Lei, H. R. Cao, and Y. F. Li, "Study on construction risk of shield tunnel under-passing existing railway by fuzzy comprehensive evaluation," Journal of Railway Science and Engineering, vol. 15, no. 5, pp. 1347-1355, Article ID 0001757, 2018.

[25] T. Y. Wang, D. Y. Xu, X. G. Zhang, J. W. Fu, and X. Z. Zhang, "Extension evaluation and warning for the excavation face landslide of the shield tunnel," Journal of Safety and Environment, vol. 20, no. 6, pp. 2052-2059, 2020.

[26] X. Liang, T. Y. Qi, Z. Y. Jin, S. Qin, and P. Chen, "Risk assessment system based on fuzzy composite evaluation and a backpropagation neural network for a shield tunnel crossing under a river," Advances in Civil Engineering, vol. 2020, no. 7, Article ID 8840200, 2020.

[27] Ministry of Housing and Urban-Rural Development of the People's Republic of China, Risk Management Code For Underground Engineering Construction Of Urban Rail Transit, Ministry of Housing and Urban-Rural Development of the People's Republic of China, Beijing, China, 2011.

[28] Ministry of Beijing Planning Commission of China, Code for Design of Metro, Ministry of Beijing Planning Commission of China, Beijing, China, 2014.

[29] Ministry of Housing and Urban-Rural Development of the People's Republic of China, Code For Construction and Acceptance of Shield Tunnelling Method, Ministry of Housing and Urban-Rural Development of the People's Republic of China, Beijing, China, 2008.

[30] B. Y. Mao, L. W. Jiang, K. Wang, and Q. Xia, "Research on the risk assessment of high-speed rail passing through large karst cavern," Journal of Railway Engineering Society, vol. 36, no. 2, pp. 21-26+32, 2019.

[31] B. Wu, M. T. Wang, and Z. Deng, "Research on stability factors and effect in upper soft and lower hard stratum tunnel," Chinese Journal of Underground Space and Engineering, vol. 15, no. 2, pp. 589-600, 2019.

[32] Z. Liu, J. Shao, W. Xu, and F. Xu, "Comprehensive stability evaluation of rock slope using the cloud model-based approach," Rock Mechanics and Rock Engineering, vol. 47, no. 6, pp. 2239-2252, 2014.

[33] M. Zhu, H. Zhu, F. Guo, X. Chen, and J. W. Ju, "Tunnel condition assessment via cloud model-based random forests and self-training approach," Computer-Aided Civil and Infrastructure Engineering, vol. 2, pp. 1-16, 2020. 